\title{
Developing a building damage function using SAR im- ages and post-event data after the Typhoon Haiyan in The Philippines
}

\author{
Bruno ADRIANO ${ }^{1}$, Erick MAS ${ }^{2}$ and Shunichi KOSHIMURA ${ }^{3}$ \\ ${ }^{1}$ Member of JSCE, Graduate Student, Graduate School of Engineering, Tohoku University \\ (Aoba 468-1-E301, Aramaki, Aoba-ku, Sendai 980-0845, Japan) \\ E-mail:adriano@geoinfo.civil.tohoku.ac.jp \\ ${ }^{2}$ Member of JSCE, Assistant Professor, International Research Institute of Disaster Science, Tohoku University \\ (Aoba 468-1-E301, Aramaki, Aoba-ku, Sendai 980-0845, Japan) \\ E-mail:mas@irides.tohoku.ac.jp \\ ${ }^{3}$ Member of JSCE, Professor, International Research Institute of Disaster Science, Tohoku University \\ (Aoba 468-1-E301, Aramaki, Aoba-ku, Sendai 980-0845, Japan) \\ E-mail:koshimura@irides.tohoku.ac.jp
}

\begin{abstract}
A building damage function was developed using very high-resolution synthetic aperture radar (VHR SAR) images and post-event building damage data after the 2013 Super Typhoon Haiyan, obtained from Tacloban city, the Philippines. Structural damage caused by the typhoon was analyzed focusing on changes in the radar footprint signatures of affected buildings. These changes are classified using a phase-based coefficient calculated from pre- and post-event COSMO-SkyMed images. The damage function is expressed as the damage ratio of structures with regard to the phase-based coefficient. The application of the estimated damage function in Tacloban city shows that from a group of structures with a POC coefficient of 0.2 or less, at least half of them are expected to be damaged.
\end{abstract}

Key Words: damage function, change detection, Typhoon Haiyan, radar remote sensing

\section{INTRODUCTION}

On November 8, 2013, the Super Typhoon Haiyan hit a portion of the Southeast Asia, in particular the south region of the Philippines. The Joint Typhoon Warning Center (JTWC) assessed the system as a Category 5 (super typhoon on the Saffir-Simpson hurricane wind scale). The super typhoon Haiyan traveled with a sustained wind speed of $315 \mathrm{kmh}^{-1}$ and made its first landfall with a maximum wind speed of approximately $230 \mathrm{kmh}^{-1}$. The typhoon made its first landfall over eastern Samar Island at 4:40 local time (LT), and its second landfall over Leyte Island at 7:00 LT (Fig.1a). As of April 17, 2014, reports on damage to people registered 6,300 dead, 28,689 injured and 1,061 missing ${ }^{13}$.

Spaceborne Earth observation is a valuable option in gathering information on the extension of damaged areas after occurrence of natural disasters. In particular, synthetic aperture radar (SAR) sensors are capable to observe the Earth's surface regardless the weather and daylight conditions. The new gen- eration of SAR sensors such as TerraSAR-X and COSMO-SkyMed (CSK) are able to provide detailed surface information for a single urban structure $^{2)}$. This information can be used to evaluate the condition of building structures after natural disasters.

In this paper, we developed a building damage function for storm surge impact using SAR images and post-event building damage data after the Typhoon Haiyan. The structural damage is analyzed using the changes on the backscattering features of building footprints between pre- and post-event SAR images.

\section{STUDY AREA AND IMAGERY DATA}

The study area is Tacloban city, located approximately at $125^{\circ} 00^{\prime \prime} \mathrm{E}, 11^{\circ} 15^{\prime \prime} \mathrm{N}$ on the northeast of Leyte Island (Fig.1). Tacloban city, with 221,174 inhabitants ${ }^{3)}$, is the largest in population within the Visayas region in the Philippines. It was one of the hardest hit places by the typhoon, which accounted for at least 2,500 of the approximately 6,300 deaths 


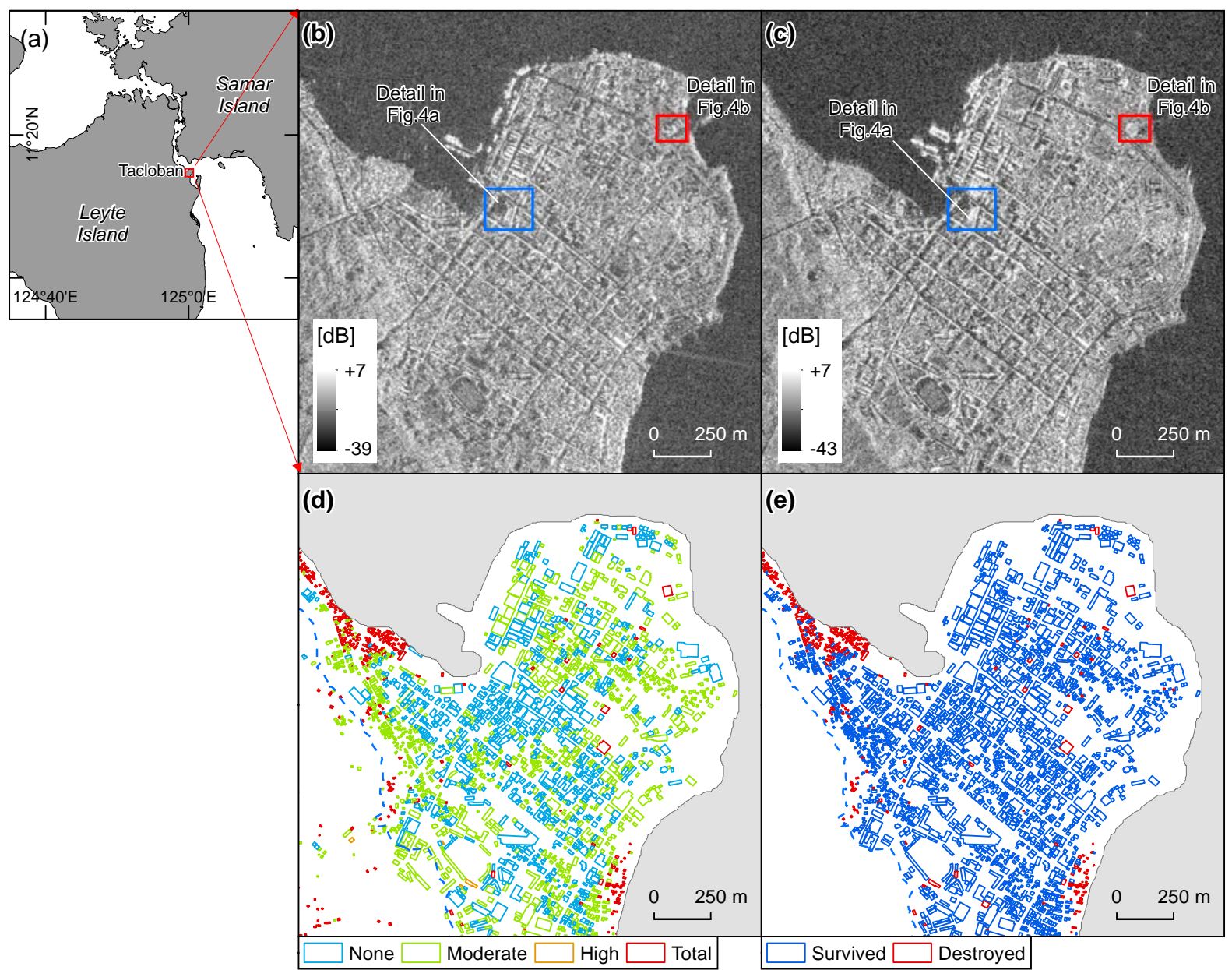

Fig.1 (a) Tacloban city. (b) Pre-event CSK data. (c) Post-event CSK data. (d) Building damage data provided by JICA in GIS-format. (e) Reclassified building damage used in this study. The blue dashed line indicates the inundation boundary of the storm surge ${ }^{7)}$.

Table 1 Number of building according to the damage level and reclassified damage level used in this study.

\begin{tabular}{cccc}
\hline & JICA & & GTD \\
\hline Total & 457 & Destroyed & 460 \\
High & 3 & Survived & 2241 \\
\hline $\begin{array}{c}\text { Moderate } \\
\text { None }\end{array}$ & 1288 & 253 & \\
\hline
\end{tabular}

in the islands ${ }^{4}$. The Japan Society of Civil Engineers (JSCE) and the Philippines Institute of Civil Engineers (PICE) conducted a collaborated field survey one month after the disaster. They reported a maximum inundation of approximately $6 \mathrm{~m}$ at Tacloban city $^{5)}$. A follow-up survey conducted by the International Research Institute of Disaster Science (IRIDeS) team from Tohoku University on mid January 2014, two months after the event, reported at least $7 \mathrm{~m}$ of inundation depth at downtown Tacloban ${ }^{6)}$.

Two SAR images from the CSK X-band sensor were used in this study. A pre-event scene acquired on August 19, 2013 (Fig.1b) and a post-event scene acquired on November 20, 2013 (Fig.1c), approxi- mately 12 days after Tacloban city was hit by the typhoon. After conducting pre-processing of the CSK images, these were resampled at $0.2 \mathrm{~m} / \mathrm{pixel}$ in a square size.

\section{(1) Building ground truth data}

In addition, the Japan International Cooperation Agency (JICA) provided a GIS file of building footprint data. These data include building damage level classification estimated through visual interpretation of pre- and post-event high-resolution optical satellite images. The building damage level was classified in 4 categories: "Total", when structures were totally destroyed, washed or blown away. "High", when the roof had been totally destroyed. "Moderate", when the roof had been partially damaged. "None", when there were not visible damage. In this study, we selected the buildings inside the inundated area previously calculated in Adriano et al. ${ }^{7}$. Finally, to construct the ground truth data (GTD), building damage levels where reclassified in 2 classes: "Destroyed" and "Survived". The spatial distribution of the reclassified damages levels, in the study area, as well as the number of buildings in 
(a) Pre-event $\left(g_{a}\right)$

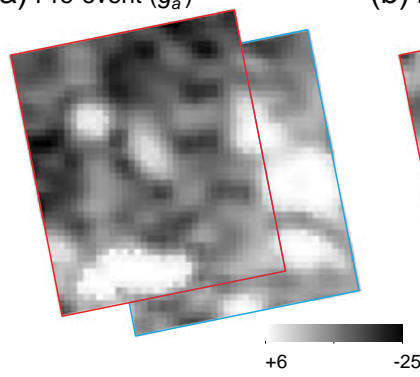

(b) Post-event $\left(g_{b}\right)$

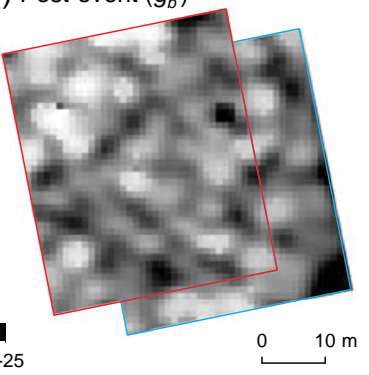

(c) $P O C_{(g a, g b)}=0.12$

(d) $P O C_{(g a, g a)}=1.0$
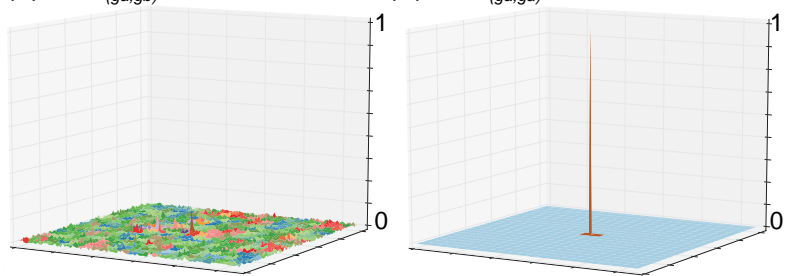

Fig.2 Example of the calculated $P O C$ function. (a) Pre-event sample CSK data $g_{b}$. (b) Post-event sample CSK data $g_{a}$ (c) $P O C$ function between $g_{a}$ and $g_{b}$. (d) POC function between two identical sample data $\left(g_{a}\right)$.

each category (Fig1d and Table 1) show that $80 \%$ of the buildings were not significantly damaged (survived), and were concentrated on the center of downtown Tacloban. Moreover, most of the destroyed buildings corresponded to the urban settlements located on the south and north of the study area. According to field surveys, these areas were highly vulnerable due to non-engineering construction $^{7)-9)}$.

\section{METHODOLOGY}

\section{(1) Phase-based change detection coefficient}

The phase-based detection method used in this study is the Phase-Only Correlation (POC) function $^{10), 11)}$. This coefficient has shown good performance to detect damage areas using moderate-resolution satellite images ${ }^{7)}$. The definition of the $P O C$ function is as follows. First, consider two images $g_{a}$ and $g_{b}$. Let $G_{a}$ and $G_{b}$ denote the 2D Discrete Fourier Transforms (2D-DFT) of the two images, as shown by equations (1) and (2).

$$
\begin{aligned}
& G_{a}=F\left\{g_{a}\right\} \\
& G_{b}=F\left\{g_{b}\right\}
\end{aligned}
$$

The cross-spectrum between the 2D-DFT images is calculated by multiplying the element-wise $G_{a}$ and the complex conjugate $G_{b}\left(\mathrm{G}_{\mathrm{b}}^{*}\right)$, shown by equation (3), where "o" denotes an element-wise product.

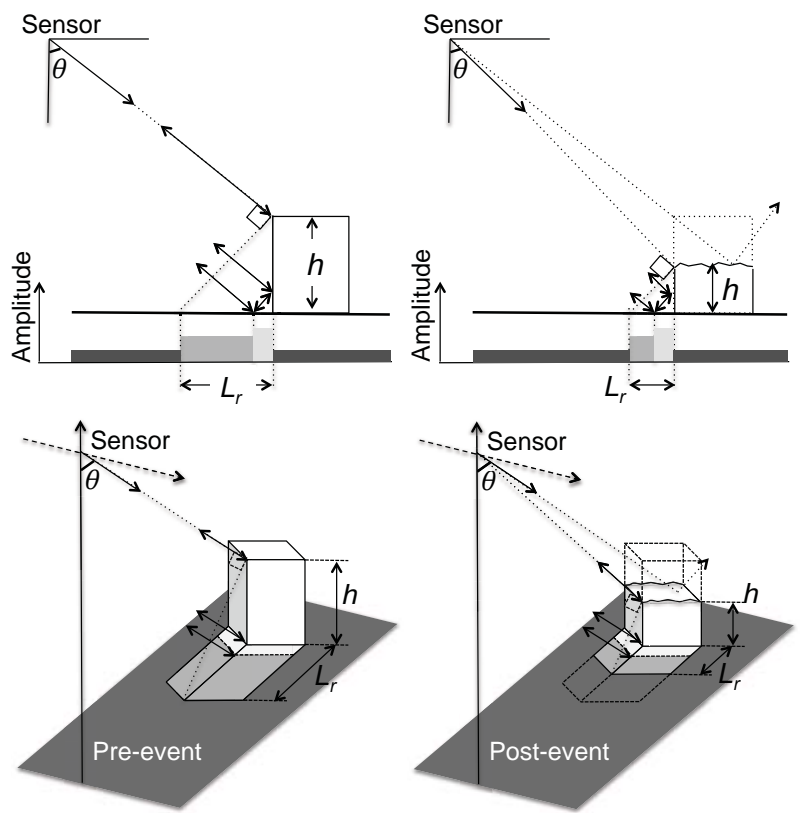

Fig.3 Schematic plots of the building footprint signature in a SAR image. Top and bottom figures show cross-section and the $3 \mathrm{D}$ view of the radar backscattering.

$$
R=\frac{G_{a} \circ G_{b}^{*}}{\left|G_{a} \circ G_{b}^{*}\right|}
$$

The $P O C$ function is given by the maximum value of the modulus of the 2D Inverse Discrete Fourier Transform (2D IDFT) of $R$, as shown by equation (4).

$$
P O C=\left|F^{-1}\{R\}\right|_{\max }
$$

The most exceptional advantage of the POC-function compared to the ordinary correlation is its accuracy in image matching ${ }^{10), 11)}$. In general, when two images are similar, their $P O C$ value gives a peak equal to 1.0. This fact can be interpreted as a low change. On the other hand, when two images present differences, the peak drops significantly. This can be interpreted as a high change. An example of the calculation of the POC values using a sample of the CSK data from the pre- and post-event images is shown in Fig.2. The figure shows the calculated $P O C$ coefficient from a destroyed building and the details are shown in Fig.4b. The resulting coefficient from the pre- and post-event samples indicates low correlation or high changes $(P O C=0.11)$, which is consistent with the building damage level. In addition, the calculated $P O C$ value from two identical samples $(P O C=1.0)$ is also shown as a proof of concept. 
(a)

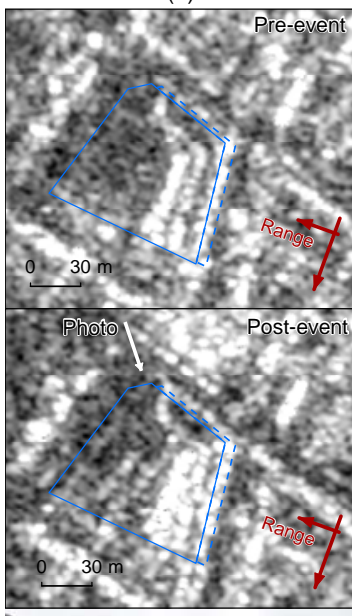

Post-event

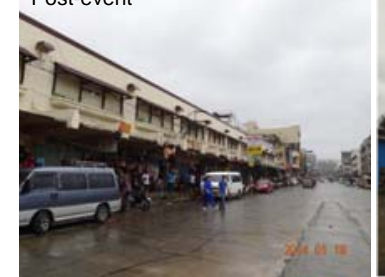

Fig.4 Pre- and post-event images and photos in-situ of each damage classification. (a) Survived building (b) Destroyed building. The solid polygons show the initial GIS footprint, and the dashed polygons shows the estimated layover-template. The dark red arrows indicate the range and azimuth direction of the radar sensor.

\section{(2) Radar remote sensing analysis}

The changes of the backscattering features in damaged buildings, such as its layover area, are strongly correlated to the extent of structural destruction $^{12)}$. A schematic plot showing the characteristics of a non-damaged and damaged building radar footprint is shown in Fig.3. The top figures show a cross-section with the radar backscattering properties and the reduction of the layover length $\left(L_{r}\right)$ in damaged structures. The bottom figures show the $3 \mathrm{D}$ view of the relation between the radar footprint or layover area and the building height $(h)$. Previous studies have employed this relation to estimate building heights using high-resolution SAR images and GIS data ${ }^{13), 14)}$. Based on Fig.3, the extent of the layover length is calculated using equation (5); which is a function of the building height and the incidence angle $(\theta)$ of the SAR image.

$$
L_{r}=\frac{h}{\tan \theta}
$$

In this study, we estimated the layover area of non-damaged structures from the pre-event SAR scene. Then these areas are used to construct a mask applied in the post-event scene to conduct the change detection analysis.
The layover area for a single building is estimated by shifting its original GIS-footprint in the direction of the sensor, as shown in Fig.4. The number of times in the shifting process depends on the building height and the location of the building with respect to other buildings and streets. For instance, Fig.4a shows a 2-story building; in this case, the initial footprint was shifted 2 times. Conversely, Fig.4b shows a warehouse of approximately $15 \mathrm{~m}$ height; then, in this case the initial footprint was shifted 4 times. Then, to construct the mask of layover areas, the estimated layover is spatially added to the original footprint, as shown by the solid and dashed polygons in Fig.4. Finally, the mask, or layover-template, is used to evaluate the changes on the radar backscattering characteristics between the preand post-event SAR images. The change detection analysis is based on the $P O C$ function that is calculated from the pixels inside the mask. Examples of the change analysis are shown in Fig.4. For instance, a survived building in Fig.4a results on a POC value of 0.8 (low changes); this is consistent with the damage observed in the post-event photo. Conversely, the POC value of a destroyed building in Fig.4b resulted in 0.11 (high changes); this is also consistent with the damage level interpreted in the photo.

\section{(3) Damage function for building damage}

Building damage function, traditionally, has been developed to identify structural vulnerability against strong ground motion within the risk analysis of building structures. An extension of this concept was apply to introduce building damage functions or tsunami fragility functions for tsunami impact ${ }^{14)}$. This function gives the probability of structural damage with regard to the hydrodynamic features of tsunamis, such as inundation depth and flow velocity. In this study, we construct a damage function to evaluate the building damage ratio based on the changes on the radar footprint signature, which is defined by the $P O C$ coefficient.

To construct the building damage function, we assume that the cumulative probability $P$ of occurrence of the damage is given as equation (6).

$$
P(x)=1-\Phi\left[\frac{x-\mu}{\sigma}\right]
$$

where $\Phi$ is the standardized normal distribution function, $x$ is the POC coefficient; $\mu$ and $\sigma$ are the mean and standard deviation of $x$, which are obtained from equation (7).

$$
x=-\sigma \Phi^{-1}+\mu
$$




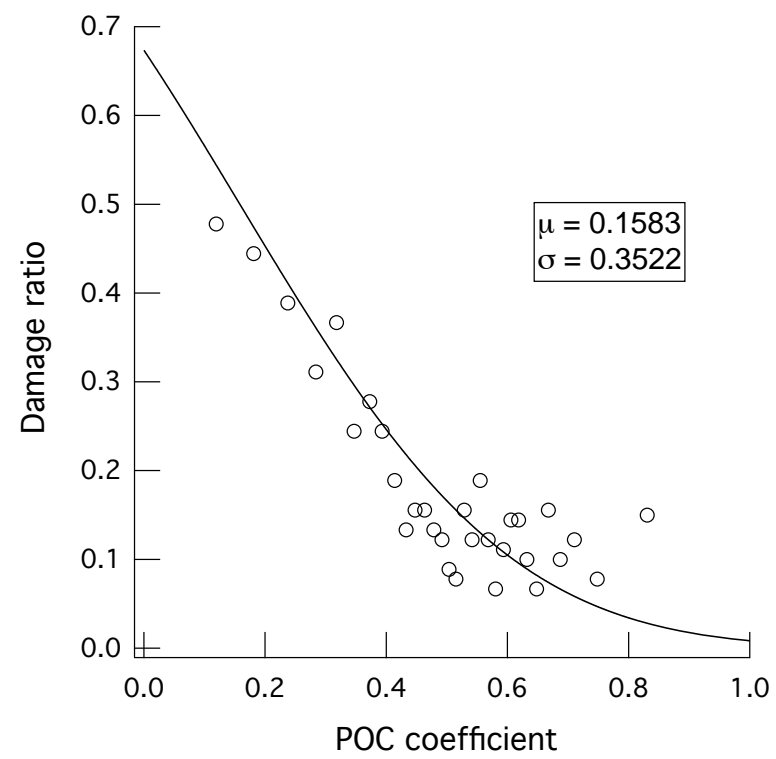

Fig.5 Damage function for building destruction, in terms of the changes of the footprint backscattering features between the pre- and post- event SAR images, which is expressed by the $P O C$ function. The circles indicate the distribution of the damage ratio.

To calculate the mean and standard deviation in equation (7), the buildings are sorted in increasing order according to the $P O C$ coefficient values. Then, we divide into groups of 90 buildings in each sample. Next, a damage ratio is calculated by dividing the number of destroyed buildings over the total number of buildings in each sample. The corresponding change coefficient for each group is given by the average value of the $P O C$ coefficient within the range of the sample. Finally, the two statistical parameters of damage function $(\mu$ and $\sigma)$ are obtained by plotting $x$ and the inverse of $\Phi^{-1}$ on normal probability papers, and performing the least-square fitting of this plot. Throughout the regression analysis, the parameters are determined as shown in Fig.5. The proposed function does not show damage ratios greater than $70 \%$ because there are few buildings in the whole sample. Nevertheless, this curve suggests that at least $50 \%$ of a group of structures may be damaged when their corresponding $P O C$ coefficient are less than 0.2. The proposed function can be used as a measure to assess the damage due to the potential storm surge and waves impact.

Finally, to verify the applicability of the proposed damage function to conduct damage detection, the building damage were classified into 4 damage levels following the ground truth data (GTD) provided by JICA: (i) 0.00 to 0.15 for "None" damage, (ii) 0.16 to 0.30 for "Moderate" damage, (iii) 0.31 to 0.50 for "High" damage, and (iv) 0.51 to 1.00 for "Total" damage (Fig.6). In general, the spatial distribution of building damage using the damage function (Model) correlates with the damage levels

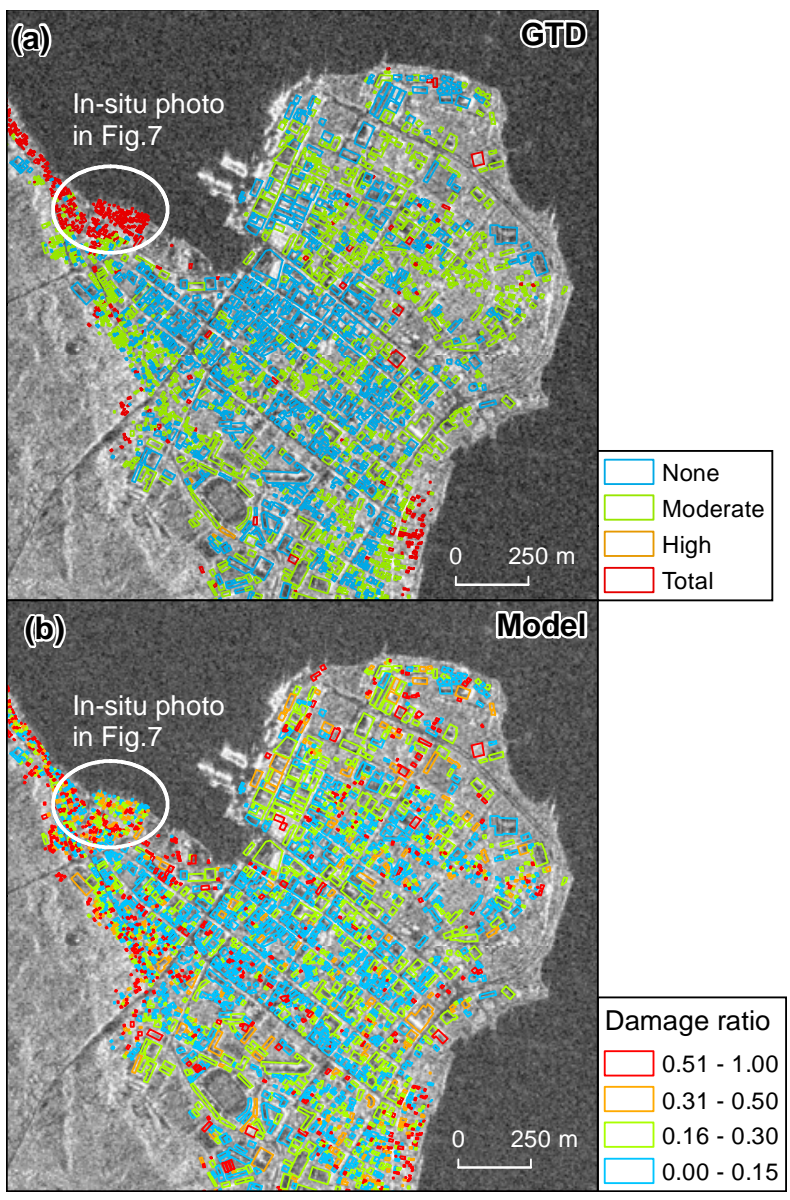

Fig.6 Application of the estimated damage function. (a) GTD used in this study. (b) Building damage ratio estimated using the proposed damage function. The white ellipse shows the area where the damage function cannot reproduce the interpreted damage levels. This might be due to the rapid and informal reconstruction of this area.

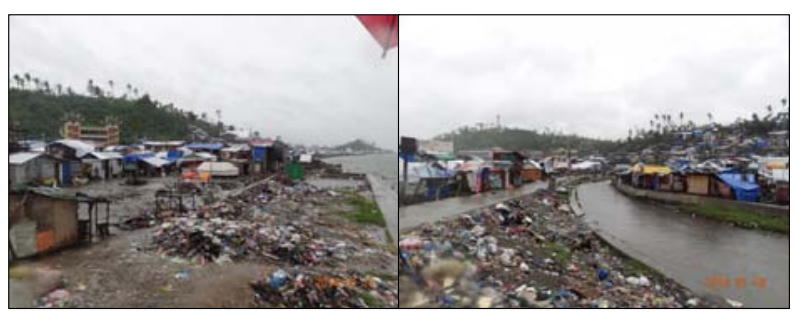

Fig.7 In-situ photos from the areas that were informally reconstructed few days after the event, which might cause the false detection from a post- SAR image, acquired almost two weeks after the event.

observed in the GTD. In particular, the damage levels at the center of downtown Tacloban are consistently lower in the Model and the GTD; this was also observed in post-event field surveys ${ }^{6), 8}$. Conversely, the area inside the white ellipse in Fig.6 shows low damage ratio, which is not consistent with the GTD. This might be because footprint sizes of houses located at this area are relatively small to be well represented in the SAR images. In addition, based on the post-event field survey), 8), the houses at this area were rapidly reconstructed few days after the 
event, which might cause the false detection from a post- SAR image acquired almost two weeks after the event when several houses were informally reconstructed, as shown in Fig.7.

\section{CONCLUDING REMARKS}

A building damage function was constructed using the high-resolution SAR data (COSMO-SkyMed images) and post-event building damage data for the 2013 Typhoon Haiyan that hit the city of Tacloban. The phase-based change detection method was used to conduct the change analysis. The damage function shows the damage ratio of structures with common $P O C$ coefficient values. The damage function can be used as a measure to assess the possible extent of damage due to typhoon impacts. However, note that the damage function developed in the present study is from the typhoon that hit Tacloban city, which includes storm surge and wave impacts. Therefore, they might not be applicable as a universal measure of typhoon impact or damage and is expected to serve as a tool for damage estimation of future events in Tacloban city.

ACKNOWLEDGMENT: This research was supported by the J-RAPID program from the Japan Science and Technology Agency (JST) and IRIDeS Research Grant (A-1).

\section{REFERENCES}

1) National Disaster Risk Reduction and Management Council: Effects of Typhoon 'Yolanda'; SitRep: No108-03APR2014. 2014.

2) Ferro A., Brunner D., and Bruzzone L.: Automatic Detection and Reconstruction of Building Radar Footprints From Single VHR SAR Images, IEEE Trans. Geosci. Remote Sens., vol. 51, no. 2, pp. 935-952, 2013.

3) National Statistics Office: Population and Annual Growth Rates for The Philippines and Its Regions, Provinces, and Highly Urbanized Cities; 2010 Census and Housing Population. 2010.

4) Mahar A., Lagmay F., Agaton R. P., Allen M., Bahala C., Brianne J., Briones L. T., May K., Cabacaba C., Vincent C., Caro C., Dasallas L. L., Anne L., Gonzalo L., Ladiero C. N., Phillip J., Theresa M., Mungcal F., Victor J., Puno R., Marie, Ramos A. C., Santiago J., Kenneth J., and Tablazon J. P.: Devastating storm surges of Typhoon Haiyan, International Journal of Disaster Risk Reduction, vol. 11, pp. 1-12, 2014.

5) Tajima Y., Yasuda T., Pacheco B. M., Cruz E. C., Kawasaki K., Nobuoka H., Miyamoto M., Asano Y.,
Arikawa T., Ortigas N. M., Aquino R., Mata W., Valdez J., and Briones F.: Initial Report of Jsce-Pice Joint Survey on the Storm Surge Disaster Caused By Typhoon Haiyan, Coast. Eng. J., vol. 56, no. 01, p. 1450006, 2014.

6) Mas E., Bricker J., Kure S., Adriano B., Yi C., Suppasri A., and Koshimura S.: Survey and satellite damage interpretation of the 2013 Super Typhoon Haiyan in the Philippines, Nat. Hazards Earth Syst. Sci., vol. 15, pp. 805-816, 2015.

7) Adriano B., Gokon H., Mas E., Koshimura S., Liu W., and Matsuoka M.: Extraction of damaged areas due to the 2013 Haiyan typhoon using ASTER data, in IGARSS 2014 and 35th CSRS, IEEE Geoscience and Remote Sensing Society (GRSS) and the Canadian Remote Sensing Society (CRSS), pp. 2154-2157, 2014.

8) Mas E., Kure S., Bricker J., Adriano B., Yi C., Suppasri A., and Koshimura S.: Field survey and damage inspection after the 2013 Typhoon Haiyan in The Philippines, in Coastal Engineering Conference of the Japan Society of Civil Engineers Vol. 70, No. 2, p. I_1451-I_1455, 2014.

9) Bricker J., Takagi H., Mas E., Kure S., Adriano B., Yi C., and Roeber V.: Spatial variation of damage due to storm surge and waves during Typhoon Haiyan in the Philippines, in Coastal Engineering Conference of the Japan Society of Civil Engineers Vol. 70, No. 2, p. I_231-I_235, 2014.

10) Takita K., Aoki T., Sasaki Y., Higuchi T., and Kobayashi K.: High-accuracy subpixel image registration based on phase-only correlation, IEICE Trans. Fundam. Electron. Commun. Comput. Sci., vol. E86-A, no. 8, pp. 1925-1934, 2003.

11) Ito K., Nakajima H., Kobayashi K., Aoki T., and Tatsuo H.: A fingerprint matching algorithm using phase-only correlation, IEICE Trans. Fundam. Electron. Commun. Comput. Sci., vol. E87-A, no. 3, pp. 682-691, Nov. 2004.

12) Gokon H., Post J., Stein E., Martinis S., Twele A., Muck M., Geiss C., Koshimura S., and Matsuoka M.: A Method for Detecting Buildings Destroyed by the 2011 Tohoku Earthquake and Tsunami Using Multitemporal TerraSAR-X Data, IEEE Geosci. Remote Sens. Lett., vol. 12, no. 6, pp. 1277-1281, 2015.

13) Yamazaki F., Liu W., Mas E., and Koshimura S.: Development of building height data from high-resolution SAR imagery and building footprint, in Safety, Reliability, Risk and Life-Cycle Performance of Structures \& Infrastructures - Deodatis, Ellingwood \& Frangopol (Eds), pp. 5493-5498, 2013.

14) Liu W., Yamazaki F., Adriano B., and Mas E.: Development of Building Height Data in Peru from High-Resolution SAR Imagery, J. Disaster Res., vol. 9, no. 6, pp. 1042-1049, 2014.

15) Koshimura S., Oie T., Yanagisawa H., and Imamura F.: Developing fragility functions for tsunami damage estimation using numerical model and post-tsunami data from Banda Aceh, Indonesia, Coast. Eng. J., vol. 51, no. 3, pp. 243-273, 2009.

(Received March 18, 2015) 